\title{
Experiences field application of intern nursing students in public health internship: A qualitative study
}

\author{
Şerife Zehra Altunkürek ${ }^{1}$, Sema Babat ${ }^{2}$ \\ (1) University of Health Sciences, Gulhane Faculty of Nursing, Department of Public Health Nursing, Ankara, Turkey \\ (2) University of Health Sciences, Gulhane Faculty of Nursing, Ankara, Turkey
}

Date submitted:

July 13, 2018

Date accepted:

Oct 25, 2018

Online publication date:

March 15, 2019

\section{Corresponding Author: \\ Şerife Zehra Altunkürek \\ Health Sciences University, Gulhane Faculty of Nursing, Public Health Nursing Department, Ankara, Turkey serifezehra.altunkurek@sbu. edu.tr}

Keywords: Intern nurse, student, public health, field application, qualitative study.

\begin{abstract}
Aims:This is a qualitative study which aims to find out the experiences that senior intern nursing students, who have public health nursing course within the scope of nursing education, experience in relation to participating in field application for the first time.
\end{abstract}

Methods:The study data was collected by means of depth interview technique using flow form consisting of semi-structured questions. This is a study conducted to 30 intern nursing students in total in public health internship group in 2017-2018 academic year at Health Sciences University Gülhane Nursing Faculty.

Results:In accordance with the data obtained as a result of focus group interviews with intern nursing students, their views on the field applications during public health internship were divided into three themes as "Intern nurses' approach to field applications", "The contribution of field applications in the professional competence of intern nursing students" and "field application feedback of intern nursing students". Intern nursing students stated that public health internship was different than clinical practices and they were anxious and concerned before the internship. In addition, they also expressed that they were happy to communicate with the public and they used their educational roles actively during field applications.

Conclusions:Determining the students' thoughts on field application, discussing these thoughts and making inferences have been important in terms of identifying the deficiencies in this field. This study indicates that educations to be given to students for reducing their concerns about field applications and adapting to field applications will be beneficial.

\section{Introduction}

The primary aim of nursing education is closely related to teaching theory and practice on nursing profession. In that respect, integrating theory and practice which are the two fundamental elements of education program and clinical experiences of nursing students are important in terms of profession (1). The diversity and frequency of the practice is an important element when turning theoretical information that students get in the school environment into behaviour in the fields of clinical practice (2).

In many parts of the world, nursing schools arranged their final year as internship practices in which educators provide counselling and students work with clinic nurses (3). With this purpose, students are enabled to practice in various clinical application fields in the last year of their education. In addition, internship program allows student to observe their role models in clinical environment, carry out applications by taking responsibility, make decisions and work as a team member (4).

In an aspect of the internship program, there is the field of public health nursing which constitutes protective healthcare services. The aim of this field is to focus on monitoring, protecting and supporting the health of communities by means of using nursing and social and public health sciences (5). Public health nursing is considered as a special field and unlike other nursing fields, it works within the community outside the hospitals where treatment services are provided (6). The purpose of public health nursing is "healthy population" and its service area is "everywhere this population lives". The individual, family, environment and the community are addressed and every factor is assessed. Studies are carried out on the family basis and family participation is enabled. They observe people in their own natural environment and see potential risks better. In these applications, service is provided with the purpose of reaching the community and individuals and finding out whether they have a disease, teaching them how to protect from existing health risks and improving medical condition (7). In addition to these, public health nursing internship program allows the student to implement nursing roles such as case management, advocacy and leadership actively other than caregiving roles in the clinical application (8).

When necessary literature review is made, several studies 
which question the clinical application process, adaptation, experience and perspectives of the interns were reached $(1,2,3$, $4,9,10)$. However, adequate number of studies which reflect the internship experiences of the students in primary healthcare services outside the hospital could not be reached (11). In that direction, the study was carried out with the idea of presenting the experience of senior intern nursing students who have public health nursing course within the scope of nursing education about participating in the field application for the first time, identifying the problems with directly or indirectly affected perspectives and offering solutions.

\section{Methods}

Participants and Data: The study was conducted at Health Sciences University Gülhane High School of Nursing in 20162017 academic year. The study population consists of senior intern students. This study was planned with the purpose of presenting the students' experience in relation to participating in the field application for the first time as a qualitative study based on descriptive analysis. Qualitative study designs have a flexible structure in which there is no rule determined for sample size, but the sample size is determined in accordance with the study question (12). For that reason, sample size is determined on the basis of information need. The principle that guides sample size is data saturation. As sample, 30 intern nursing students in public health internship were interviewed using goal-directed election method among improbable sampling methods. The interview guide consisting of ten questions which was prepared in the light of the literature was used to guide the researchers during the interview $(1,2,3,11)$. During the interview, nursing students' views, expectations, experiences about intern field applications and the contributions of public health internship, etc. were questioned. The data was collected with face to face interview technique and semi-structured depth individual interview. The interview took 35 minutes on average. A voice recorder was used to record the data. Görüşmeler, öğrencilerin görev aldığı toplum sağlığı ve aile sağlığı merkezinde gerçekleştirilmiştir.

Ethical Committee Approval: Approvals regarding the study were taken from Health Sciences University, Non-Invasive Clinical Researches Ethical Committee. Written and verbal consent was taken from all students who will participate in the study using the Informed Consent Form which gives information about the objective and method of the study.

Data Assessment: The study was analysed in three stages as description, analysis and interpretation (13). Voice recordings of all interviews were transcribed on the same day. Information obtained from voice recordings with theme analysis method was assessed.

\section{Results}

\section{Intern Nursing Students Introductory Results}

Intern nursing students are the students who are in the last year of the 4-year integrated education system and spend this year in the clinic and field. The age range of the senior intern nursing students is 21-22. Intern nursing students who carried out the public health internship at Community Health Centre and Family Health Centre using theoretical and practical information took active roles for six weeks.

\section{Study Results Which Assess Field Applications}

In accordance with the data obtained as a result of interviews made with intern nursing students, their views on the field applications during public health internship were divided into three themes as "Intern Nurses' Approach to Field Applications", "The Contribution of Field Applications in the Professional Competence of Intern Nursing Students" and "Field Application Feedback of Intern Nursing Students".

Intern nursing students stated that they were anxious and concerned before the field applications. Intern nursing students who had previous clinical experience said that they had anxiety as they were going out to the field for the first time.

"I am concerned because of the tension, uncertainty of a new internship and not having a command on the process."

"I was afraid of having communication problems and attitudes towards us at the institution that I would go before the internship. But I did not have any problem in field applications at the community health centre."

Before the internship, the intern nursing students used to think that public health personnel at the institutions would prevent the decisionmaker role and they were going there just to reduce the workload.

"I think our only task is to input data in the system as intern nursing students at the Family Health Centres-Community Health Centres. I would like to be the decision making and implementing party."

The idea of having contact with the individuals outside the hospital environment caused curiosity and excitement among the intern nursing students.

"I understood that the people who apply to the Family Health Centre should be described as 'individual' rather than 'patient'”.

Participation of both the clinical education nurse and the internship advisor participate in the skills together with the students in the clinics provides motivation to the intern nursing students. However, decision making position at the primary healthcare centres caused timidity among the students initially.

The students did not refrain from indicating the flaws seen within the scope of field applications. Saha uygulamaları kapsamında öğrenciler yaşadığı güçlükleri ve görülen aksaklıkları belirtmekten kaçınmamışlardır. Olarak değiştirilecek!!!

"The high number of patients increases the nurse's workload and demotivates us. For that reason, I have seen that the attention that should be paid to the patients has reduced. For example, the doctor and nurse's failing to work as a team during pop-smear sampling is an unacceptable fault."

When they are asked if they know the way to access information, most of the students emphasised that the courses they took in the first years were sufficient, but they should be repeated before the internship. The advisor's help in terms of literature and resource's and being close to the student encouraged intern nursing students for pre-field education and public health field.

"I would like that a discussion environment was created during internship and we were informed better about accessing information. I would like that the convenience of the titles we find was discussed."

"I have worked as adapted to my place and location with high motivation in terms of using the theoretical information that I had, providing benefit to the other party and doing my job pro- 


\section{fessionally."}

"We did not contact directly the sick people, but everyone who have the potential to become sick. The educating role of the nurse was more prominent than treatment for us."

"And I understood how to communicate with people. For example, I saw that information should be given according to the education level, belief and family structure of the person."

One of the situations revealed during the interviews with intern nursing students is that the harmony of intern nursing students with the personnel is positive.

"The personnel at the community health centre was experienced in practice and well-equipped in terms of theoretical knowledge. They shared their knowledge with us. They made us feel their support when we are anxious. It was a very beautiful working environment. Communicating with various people on the field enabled me to improve myself in this field."

Nursing students have made their best to ensure that the education fits the purpose and they influenced the environment about raising awareness.

"Getting to know the families in advance and determining which information they need and how they can access such information and providing a planned and programmed education to them will both enhance us professionally and improve to provide benefit to them."

"Sometimes I think that communicating with the patient is more important than the intervention. I have seen that the patients that we failed to communicate with rejected the application. Especially dissatisfaction of the Syrians when we go from door to door for recording has made the application difficult."

"I have seen that it was not possible to approach some people during field applications. I have observed that the reason for this is lack of knowledge and their unwillingness to communicate with the healthcare personnel."

"I have seen that the high number of patients increases the nurses' workload and demotivates them. For that reason, I have seen that the attention that should be paid to the patients has reduced. The doctor and nurse's failing to work as a team during smear sampling is an unacceptable fault."

It was stated that one of the disturbing circumstances during internship was rude and disrespectful attitude and behaviour of some of the personnel towards the nurse or intern nursing student.

"I have seen how the theoretical information that we learn at school work in the field applications. I have seen how it is arranged, what the procedures are and how the applications are realized for Syrian children. I had the opportunity to examine their living conditions and living areas."

Intern nursing students who had a high chance of encountering various population before the field applications had been timid before the screening programs, but they received positive feedback.

"I liked that students embraced us at schools. The continuation of the connection after the vaccination gave professional satisfaction."

"I liked the activeness of the nurses and their interest and attitude towards the individuals they are responsible for. The opportunities provided for screening tests and nurses' encouraging the patients in this matter set an example for me."

"We had prejudices. On the contrary, the role model behaviour of the personnel has increased willingness and motivation towards field applications among us."

"The personnel at the community health centre was experienced in practice and well-equipped in terms of theoretical knowledge. They shared their knowledge with us. They made us feel their support when we are anxious. It was a very beautiful working environment. Communicating with various people on the field enabled me to improve myself in this field."

Intern nursing students provided every individual from all segments of the society holistic and humanistic approach during the field applications, including children, adolescents, pregnant women, elder people and immigrants.

"I would like that a discussion environment was created during internship period and learn better in terms of accessing information. I would expect that the convenience of the presentations that we prepared within the scope of in-service training was discussed and addressed a larger audience."

Intern nursing students stated that they increased their professional competence, skills and success in time and as they gain experience.

\section{Discussion}

In nursing education, internship is an application which enable students turn the theoretical information to practice and develop a professional identity (14). For this purpose, most of the nursing schools in the world and our country have arranged the final year of the nursing education program as internship applications which is carried out by educators and clinic nurses together $(1,9,14,15,16,17)$. Public health field application which is included in the internship program in our study contains community health centres and family health centres unlike the clinic. When their thoughts on field applications were asked, intern nursing students primarily stated that their anxiety, stress, uncertainty and fear levels were high. Jouzi et al. (18) stated that students are concerned about the clinical application and this arises from making a mistake. Altay and Öz (11) determined that most of the students are excited before the home visits within the scope of public health internship and only $5 \%$ of them feel fear. They stated that it arises from the fact that students are in their final year and trust in their professional knowledge more. In addition, students stated that they are anxious about and afraid of having communication problems with the patients and personnel at the institution they will go. Although the students had previous clinical application experience, these fears may arise from providing healthcare services in a different region and outside the hospital environment, in a different system. Jaffari et al. (2008) stated that communication skills were not covered adequately in the nursing curriculum in Iran and therefore the students are afraid of not being able to communicate with personnel and patients in the clinic applications.

The reform package presented as "Family Physician Model" in our country with the Law No 5258 was started in Düzce in 2005 and family physician system was adopted in all 81 provinces as of the end of 2010 (20). In this system, family physician and family health personnel are obliged to provide protective healthcare services and primary diagnosis, treatment and reha- 
bilitative services to people registered to themselves (20). However, the articles regarding personnel rights, duties, authorities and responsibilities of the healthcare personnel working in the system are not on adequate level in the Family Physician Application Regulations (21). In our study, it was found that students only input data, the workload of nurses due to the high number of patients reduces motivation and the physician and nurses' lack of team spirit causes unwillingness to work in this field. In their study, Dereli et al. (2014) stated that students do not find the quality of the services provided at family health centre adequate and most of them did not want to work at the family health centre similar to our study.

Public health nursing field application enables the development of students' roles of using and improving professional knowledge and skills, decision making, problem solving and understanding the society better with interpersonal relations and communication skills. In our study, while students stated that they were anxious about and afraid of communicating before the application, they stated that communication was as important as treatment during the application. In addition, they also stated that communicating with various people on the field improved them professionally in a positive manner. Introducing the field before the practice and discussing the operation of the system together with the educators may encourage students in terms of communication.

Roles of a professional public health nurse may be grouped as caregiver, educator, spokesman, leader and researcher (11). In addition, public health nurse has the authority to plan individual and group education, prepare and assess the education environment with the purpose of improving health and preventing diseases (22). In our study, students stated that they planned health educations, but could not communicate their presentations to the community and they are sad because nurses are unwilling in this respect. Altay and Öz (2016) determined that students are aware of their professional roles during home visits in field application and they used their educator and executive roles the most. In our study, the fact that students are under the responsibility of nurses depending on the family health centre and community health centre may be interpreted as that they could not implement their educator roles actively since they could not provide education to the community and individual independently.

In accordance with the results obtained from the study, senior intern nursing students had the opportunity to improve their skills in relation to implementing theoretical information, turning into professionals, using and improving professional knowledge and skills, decision making, problem solving and understanding people with interpersonal relations and communication skills within the scope of public health internship. Public health nursing field application prepared intern nursing students for the profession within the concepts of place-timespace with problem solving and critical thinking skills by only questioning individuals without judging them. However, it was determined that intern nursing students did not have adequate information about family health centre and community health centre system. It is suggested that students are informed better about the family health centre and community health centre system, working conditions and policies outside hospitals are brought to preferable level and more and comprehensive studies are conducted on field applications.

\section{Acknowledgment}

Author contributions: Concept; S.Z.A and S.B., design; S.Z.A., supervision; S.Z.A., materials; S.Z.A., data collection \&/or processing; S.Z.A and S.B., analysis \&/or interpretation; S.Z.A and S.B., literature search; S.Z.A and S.B., writing; S.Z.A and S.B., critical review; S.Z.A., No financial support was received from any source for this work.

\section{Conflict of Interest}

The authors declared they do not have anything to disclose regarding conflict of interest with respect to this manuscript.

\section{References}

1. Bigdeli S, Pakpour V, Aalaa M, et al. Clinical learning environments (actual and expected): Perceptions of Iran University of Medikal Sciences nursing students. Med J Islam Repub Iran. 2015; 289 (173):1-8.

2. Pai HC. An integrated model for the effects of self-reflection and clinical experiential learning on clinical nursing performance in nursing students: A longitudinal study. Nurse Educ Today. 2016; 45:156-162.

3. Sabancıogulları S, Dogan S, Kelleci M, Avcı D. The Determination of Final Year Nursing Students' Perceptions on Internship Program. DEUHYO. 2012; 5(1):16-22.

4. Tosun N, Oflaz F, Akyuz A, et al.. Evaluation of the expectations of nursing school students from the intern education program and of their acquisitions and suggestions at the end of the program. Gulhane Med J. 2008; 50:164-171.

5. Canadian Public Health Association. Public Health Nursing Practice In Canada Roles And Activities, Forth Edition;2010. http://www.cpha.ca/uploads/pubs/3-1bk04214. pdf. Accessed May 15, 2018.

6. Erci B. Public Health Nursing. Ankara: Göktuğ Yayıncılık; 2009.

7. Daghan S. "What is the Meaning of "Being a Nurse through Public Health Nursing Philosophy"?. DEUHFED. 2017; 10(2): 107-112.

8. Allender J, Rector C, Warner K. Community health nursing: Promoting \& Public's health. 7th ed. China: Lippincott Williams \& Wilkins;2010.

9. Karimi S, Haghani F, Yamani N, Kalyani MN. Exploring the perception of nursing students about consequences of reflection in clinical settings. Electronic Physician. 2017; 9(9): 5191-5198.

10. Lapeña-Moñux YR, Cibanal-Juan L, Orts-Cortés MI, Maciá-Soler ML, Palacios-Ceña D. Nurses' experiences working with nursing students in a hospital: a phenomenological enquiry. Rev Latino-Am Enfermagem. 2016;24:e2788. http://www.scielo.br/scielo.php?scrip$\mathrm{t}=$ sci_arttext\&pid=S0104. Accessed May 15, 2018.

11. Altay $B, O z O$. Last Class Students of Nursing Department Faced With Difficulties at Home Visits Within The Context Of Public Health and Professional Nursing Roles. Samsun Sağlık Bilimleri Dergisi. 2016; 1(1):1-12.

12. Yıldırım A, Simsek H. Qualitative Research Methods in Social Sciences. 7th ed. Ankara, Seçkin Yayıncılık; 2008. 
13. Aksayan S, Emiroglu N. Research Design. Erefe, I. (Ed). ). Hemşirelikte Araştırma: Illke Süreç ve Yöntemleri (Research in Nursing: Principle Processes and Methods) İstanbul, Odak Ofset; 2002.

14. Erenel Senturk A, Dal U, Kutluturkan S, Vural G. The Views of the Fourth Year Students and Nurses About Internship Practices. Hacettepe Üniversitesi Hemşirelik Fakültesi Dergisi. 2008; 15(2):16-25.

15. Kim KH. Clinical competence among senior nursing students after their preceptorship experiences. J Prof Nurs. 2007; 23(6): 369-375.

16. Harrison TM, Stewart S, Ball K, Brat MM. Enhancing the transition of senior nursing students to independent practice. J Nurs Adm. 2007;37 (6):311-317.

17. Orak S, Orhan H, Agırman O, Ozgurce B. Süleyman Demirel University Model In Nurse-Midwife Education: Isparta Health Collage Intern Students' Knowledge and Behavior about In Integrated Application in Clinical Field. SDÜ Tıp Fakültesi Dergisi. 2009; 15(3):11-16.

18. Jouzi M, Vanaki Z, Mohammadi E. Factors affecting the communication competence in Iranian nursing students: A qualitative study. Iran Red Crescent Med J. 2015; 17(3): e19660.

19. Jaffari-Golestan N, Vanaki Z, Memarian R. Organizing "nursing mentors committee": an effective strategy for improving novice nurses' clinical competency. Iran J Med Educ. 2008;7(2);236-237.

20. Dereli F. The Views of 4 th Grade Nursing Students on Family Medicine. Journal of Anatolia Nursing and Health Sciences. 2014;17(2):105-109.

21. Sonmez MO, Sevindik F. The Effect of Transformation in Health on Health Personnel: To Be Family Health Personnel. TAF Prev Med Bull. 2013;12(1):43-48.

22. Ozpulat F. Health Protection and the Development of Nurse A Role In Contemporary: Trainers For Identity. Maltepe Üniversitesi Hemşirelik Bilim ve Sanatı Dergisi, 2010; Sempozyum Özel Sayısı: 293-297. 